\title{
Rate of and Risk Factors Associated with Retinopathy of Prematurity: A Prospective Study from Kuwait
}

\author{
Mazen Al-Essa ${ }^{a}$ R.V. Azad ${ }^{b}$ Nabil Rashwana \\ aDepartment of Neonatology, Maternity Hospital, and ${ }^{\mathrm{b}}$ Department of Ophthalmology, \\ Ibn Sina Hospital, Kuwait
}

\section{Key Words}

Retinopathy of prematurity - Low birth weight . Cryotherapy

\begin{abstract}
Objective: To determine the rate of retinopathy of prematurity (ROP) among a population of preterm infants in Kuwait, and to review the risk factors associated with the disease. Methodology: A prospective cohort study of all preterm infants of less than $2,000 \mathrm{~g}$ birth weight and/or 36 weeks gestational age who were screened for ROP during 1995 at the neonatal unit of the Maternity Hospital in Kuwait. The rate of and some of the possible risk factors associated with the disease were determined. Results: A total of 130 babies were screened of which 59 (45.4\%) developed some stage of ROP. The frequency of blindness was 3 (2.3\%). Low birth weight, oxygen therapy, patent ductus arteriosus, intraventricular hemorrhage and blood transfusion were the risk factors found to be associated with the disease. However, with logis-
\end{abstract}

\begin{tabular}{ll}
\hline KARGER & (1) 1999 S. Karger AG, Basel \\
Fax +4161306 1234 $34-7571 / 99 / 0082-0115 \$ 17.50 / 0$ \\
$\begin{array}{l}\text { E-Mail karger@karger.ch } \\
\text { www.karger.com }\end{array}$ & $\begin{array}{l}\text { Accessible online at: } \\
\text { http://BioMedNet.com/karger }\end{array}$
\end{tabular}

tic regression analysis, only low birth weight and oxygen were independently associated with ROP. Conclusion: The rate of ROP in our unit is not different from that of the other centers, and low birth weight and oxygen therapy are the main risk factors associated with the disease.

\section{Introduction}

Retinopathy of prematurity (ROP) is one of the important causes of blindness and impaired vision among children [2-4, 20]. With rapid advances in the field of neonatology more extremely premature babies are surviving possibly with an increased risk of chronic illnesses including ROP. The incidence of ROP varies in different countries but there are no published figures for Kuwait. Identification of risk factors for ROP is an important task for neonatologists and different studies have identified different risk factors [5-11, $13,14,18,23]$. 
Table 1. Frequency of ROP stages

\begin{tabular}{|c|c|c|c|c|}
\hline & \multicolumn{2}{|c|}{ Right eye } & \multicolumn{2}{|c|}{ Left eye } \\
\hline & $\mathrm{n}$ & $\%$ & $\mathrm{n}$ & $\%$ \\
\hline Stage 1 & 24 & 18.5 & 24 & 18.5 \\
\hline Stage 2 & 15 & 11.5 & 16 & 12.3 \\
\hline Stage 3 & 18 & 13.8 & 15 & 11.5 \\
\hline Stage 4 & 1 & 0.8 & 0 & \\
\hline Plus disease & 2 & 1.5 & 2 & 1.5 \\
\hline
\end{tabular}

We present here the first report of the incidence of ROP in a large cohort of newborn babies in a large center in Kuwait, and identify the important risk factors.

\section{Patients and Methods}

Routine eye examination of preterm babies was first introduced in a systematic manner in Kuwait in 1995. Our neonatal center at the Maternity Hospital, Kuwait is the largest center in the country conducting around 13,000 deliveries each year. We included all babies admitted to the unit during the year of 1995 who were less than $2,000 \mathrm{~g}$ birth weight and or less than or equal to 36 weeks gestational age.

Ophthalmic examination was performed by indirect ophthalmoscopy. The pupils were dilated using $2.5 \%$ phenylephrine and $0.5 \%$ tropicamide eye drops instilled into each eye 3 times at intervals of $15 \mathrm{~min}$ prior to examination [22]. For extremely premature babies, we followed the protocol of examining them at 4 weeks of postnatal age and/or at 32 weeks corrected age, and those above 32 weeks were examined in the 1 st week of birth. If no ROP was detected at the initial examination, the infants were reevaluated once every 2 weeks until discharge and then every 4 weeks until 3 months of corrected age. If ROP was detected, the examination were performed every week until the disease started to regress. The changes of ROP were classified according to the International Classification of Retinopathy of Prematurity [4, 5]. Prospective collection of the data was done for each patient, and the following risk factors were examined; birth weight, gestational age, oxygen therapy, blood transfusion, phototherapy, presence of patent ductus arteriosus, and the use of surfactant (Survanta ${ }^{\circledR}$ ). Cryotherapy or laser treatment for threshold ROP was done under general anesthesia in another center after transporting the babies [1]. The babies were then seen weekly until the regression of the disease.

The data were entered on the SPSS database program and analyzed statistically using Student's t test for continuous variables and chi-square test for categorical variables. Stepwise logistic regression analysis was used to determine the independent variables associated with the development of ROP.

\section{Results}

A total of 130 cases each had on an average 5 examinations. The mean birth weight of the babies examined was 1,217 g (range: 700$2,000 \mathrm{~g}$ ) and the mean gestational age 30.7 weeks (range of 26-36 weeks). There were 62 males and 68 females, 15 pairs of twins, one set of triplets and a set of quadruplets. The mean corrected age at first examination was 33.1 weeks (range 30-37) and that at final examination was 39.5 weeks (range 34-68).

There were 59 babies $(45.5 \%)$ who had various stages of ROP, 3 of whom became blind. Of these, 2 were lost to follow-up but returned with a very advanced stage of the disease when surgery was not possible, and the 3rd was not improved by laser treatment. Three babies died. One baby had the disease in zone 1 of the left eye, 44 babies (33.8\%) had it in zone 2 of the right eye and $40(30.8 \%)$ had it in zone 2 of the left eye. The stages of ROP are shown in table 1 . There were 27 babies weighing more than $1,500 \mathrm{~g}$ at birth of which $3 \mathrm{had}$ ROP (11\%), while among those above 34 weeks gestation, none had the disease.

Risk factors and their relation with ROP were studied, and of these low birth weight, oxygen therapy, presence of patent ductus arteriosus, presence of intraventricular hemorrhage, receipt of blood transfusion and surfactant therapy were found to be significantly associated with the disease (table 2). With stepwise logistic regression analysis, however, only low birth weight $(\mathrm{p}<0.0005)$ and oxygen 
Table 2. Risk factors associated with ROP

\begin{tabular}{lccc}
\hline & ROP $(\mathrm{n}=59)$ & No ROP $(\mathrm{n}=71)$ & p value \\
\hline Mean birth weight, g & 1,039 & 1,216 & 0.026 \\
Oxygen therapy & $56(95 \%)$ & $52(73 \%)$ & 0.001 \\
Presence of patent ductus arteriosus & $33(56 \%)$ & $18(25 \%)$ & 0.001 \\
Presence of intraventricular hemorrhage & $20(34 \%)$ & $10(14 \%)$ & 0.01 \\
Blood transfusion & $55(93 \%)$ & $56(79 \%)$ & 0.025 \\
Surfactant therapy & $39(66 \%)$ & $30(42 \%)$ & 0.008 \\
Phototherapy & $56(95 \%)$ & $60(84.5 \%)$ & 0.08 \\
\hline
\end{tabular}

Table 3. Incidence of ROP

\begin{tabular}{|c|c|c|c|}
\hline \multirow[t]{2}{*}{ Study } & \multirow[t]{2}{*}{ Number } & \multicolumn{2}{|c|}{ Incidence of ROP, $\%$} \\
\hline & & total & severe \\
\hline \multicolumn{4}{|l|}{ Ng et al. [6] (UK) } \\
\hline (birth weight $<1,701 \mathrm{~g}$ ) & 505 & 60.1 & 6.3 \\
\hline \multicolumn{4}{|l|}{ Smith et al. [7] (Australia) } \\
\hline (birth weight < 1,501 g) & 94 & 16.0 & 4.2 \\
\hline \multicolumn{4}{|l|}{ Bassiouny [8] (Oman) } \\
\hline (birth weight < 1,501 g) & 73 & 34.0 & NA \\
\hline \multicolumn{4}{|l|}{ Maheshwari et al. [9] (India) } \\
\hline (birth weight $<1,501 \mathrm{~g}$ ) & 66 & 20.0 & 7.0 \\
\hline \multicolumn{4}{|l|}{ Present study (Kuwait) } \\
\hline (birth weight $<1,500 \mathrm{~g}$ ) & 103 & 54.3 & 8.3 \\
\hline
\end{tabular}

therapy ( $p<0.05)$ were found to be independently associated with the development of ROP.

\section{Discussion}

This study documents the cumulative incidence of ROP in a large neonatal center and is the first report from Kuwait. The frequency of ROP varies from 16 to $60 \%$ in studies around the world (table 3 ). In babies of $<1,500 \mathrm{~g}$ in our study from Kuwait the cumulative incidence of ROP was 54\% and in $8 \%$ the ROP was severe. Since this was the first time that a screening program for ROP was introduced in Kuwait, larger birth weight and gestational ages were also included [16, 17]. After logistic regression analysis [12], low birth weight and oxygen therapy were the only risk factors out of the seven factors under consideration or entered into the model, that were independently associated with ROP [21]. However, we did not specify the concentration and duration of oxygen therapy used in the babies. Some other known risk factors were not included like episodes of apnea, use of total parenteral nutrition, episodes of sepsis and some maternal risk factors [5-11, 13, 14, 18, 19, 23, 25].

Further studies taking these factors into consideration are to follow. The high rate of ROP in the multiplets can be explained by the premature low birth weight that these multiplets have. This could probably be prevented 
in some cases [15]. There was a high rate of blindness in spite of widening our inclusion criteria for screening. This can be explained by the poor compliance for follow-up by the parents who could not recognize blindness in their babies. This can be avoided by more frequent eye examination and by not discharging any suspicious cases from the hospital during the early stages of ROP.

Our ROP management confirmed the usefulness of cryotherapy with a $100 \%$ success rate, and a possible role for laser treatment (66\% success rate) [24]. This is in conformity with other studies.

\section{References}

1 Retinopathy of Prematurity: Guidelines for Screening and Treatment. Report of a Joint Working Party of the Royal College of Ophthalmology and the British Association of Perinatal Medicine. Early Hum Dev 1996;46:239-258.

2 Bossi E, Koerner F: Retinopathy of prematurity. Intensive Care Med 1995;21:241-246.

3 Flynn JT: Retinopathy of prematurity: Perspective for the nineties. Acta Ophthalmol Scand Suppl 1995;214:12-14.

4 Fledelius HC: Pre-term delivery and subsequent ocular development: A 7-10 year follow-up of children screened 1982-84 for ROP. Acta Ophthalmol Scand 1996;74:301305.

5 Keith CG, Doyle LW: Retinopathy of prematurity in infants weighing 1000-1499 g at birth. J Paediatr Child Health 1995;31:134-136.

$6 \mathrm{Ng} \mathrm{YK}$, Fielder AR, Shaw DE, Levene MI: Epidemiology of retinopathy of prematurity. Lancet 1988;ii: 1235-1238

7 Smith J, Spurrier N, Goggin M: Retinopathy of prematurity in a South Australian neonatal intensive care unit. Aust NZ J Ophthalmol 1995; 23:49-54

8 Bassiouny MR: Risk factors associated with retinopathy of prematurity: A study from Oman. J Trop Pediatr 1996;42:355-358.

9 Maheshwari R, Kumar H, Paul VK, Singh M, Deorari AK, Tiwari HK Incidence and risk factors of retinopathy of prematurity in a tertiary care newborn unit in New Delhi. Natl Med J India 1996;9:211-214.
10 Bianchi PE, Salati R, Guagliano R, Traselli GP, Rondini G, Trimarchi F: Review of experience with retinopathy of prematurity from the $\mathrm{Pa}$ via registry (1991-1993). Eur J Ophthalmol 1996;6:187-191.

11 Teoh SL, Boo NY, Ong LC, Nyein MK, Lye MS, Au MK: Duration of oxygen therapy and exchange transfusion as risk factors associated with retinopathy of prematurity in very low birthweight infants. Eye 1995;9: 733-737.

12 Scott SC, Goldberg MS, Mayo NE: Statistical assessment of ordinal outcomes in comparative studies. J Clin Epidemiol 1997;50:45-55.

13 Nødgaard H, Andreasen H, Hansen $\mathrm{H}$, Sørensen HT: Risk factors associated with retinopathy of prematurity (ROP) in Northern Jutland, Denmark 1990-1993. Acta Ophthalmol Scand 1996;74:306-310.

14 Termote J, Schalij-Delfos NE, Cats BP, Wittebol-Post D, Hoogervorst BR, Brouwers HA: Less severe retinopathy of prematurity induced by surfactant replacement therapy. Acta Paediatr 1996;85:1491-1496.

15 McKibbin M, Dabbs TR: Assisted conception and retinopathy of prematurity. Eye 1996;10:476-478.

16 Jandeck C, Kellner U, Kossel H, Bartsch M, Versmold HT, Foerster $\mathrm{MH}$ : Retinopathy of prematurity in infants of birth weight $>2000 \mathrm{~g}$ after haemorrhagic shock at birth. $\mathrm{Br} \mathrm{J}$ Ophthalmol 1996;80:728-731.

17 Fledelius HC: Central nervous system damage and retinopathy of prematurity: An ophthalmic follow-up of prematures born in 1982-84. Acta Paediatr 1996;85:1186-1191.

18 Holmstrom G, Thomassen P, Broberger U: Maternal risk factors for retinopathy of prematurity: A popu- lation-based study. Acta Obstet Gynecol Scand 1996;75:628-635.

19 Saunders RA, Donahue ML, Christmann LM, Pakalnis AV, Tung B, Hardy RJ, Phelps DL: Racial variation in retinopathy of prematurity: The Cryotherapy for Retinopathy of Prematurity Cooperative Group. Arch Ophthalmol 1997;115:604608.

20 Knight-Nanan DM, Algawi K, Bowell R, O'Keefe M: Advanced cicatricial retinopathy of prematurity: Outcome and complications. Br J Ophthalmol 1996;80:343-345.

21 Cunningham S, Fleck BW, Elton RA, McIntosh N: Transcutaneous oxygen levels in retinopathy of prematurity. Lancet 1995;346:14641465.

22 Laws DE, Morton C, Weindling M, Clark D: Systemic effects of screening for retinopathy of prematurity. Br J Ophthalmol 1996;80:425-428.

23 Pennefather PM, Tin W, Clarke MP, Fritz S, Strong NP: Retinopathy of prematurity in a controlled trial of prophylactic surfactant treatment. Br J Ophthalmol 1996;80: 420-424.

24 Ling CS, Fleck BW, Wright E, Anderson C, Laing I: Diode laser treatment for retinopathy of prematurity: Structural and functional outcome. Br J Ophthalmol 1995;79: 637-641.

25 Johnson L, Quinn G, Abbasi S, Gerdes J, Bowen F, Bhutani V: Severe retinopathy of prematurity in infants with birth weight less than 1250 grams: Incidence and outcome of treatment with pharmacologic serum levels of vitamin $\mathrm{E}$ in addition to cryotherapy from 1985-1991. J Pediatr 1995; 127:632-639. 